\title{
Mario Thériault, Échographie du Nord (Poésie).
}

\author{
Moncton : Éditions Perce-Neige, 1992. 50 p.
}

Né à Baie Sainte-Anne au Nouveau-Brunswick en 1962, Mario Thériault travaille aujourd'hui à Télé-Ontario, à Toronto, après des séjours à Vancouver et à Paris. Avec ce volume touchant à l'étude sonore du Nord, isolement et froidure, dont la couverture laisse peu de doute sur la thématique générale - isolement et difficulté de communication - il nous offre une réflexion intéressante sur le regard et la lumière en particulier. En effet, le nord, comme nous l'arrenait il y a quelques années une exposition sur les peintres canadiens et scandinaves, c'est aussi une lumière intense, qui peut faire surgir l'ignoré, le nouveau, le non-encoredit, comme dans le poème, par ailleurs situé en Suède, "Le pardessus : »
je trappe le nord
dépose ma trappe
avec la minutie du maître
trappe spéciale pour capter la lumière...
je frise $l^{\prime}$ Eldorado du nacre polaire...
au bord du nord j'ai la confiance
de la lumière
pas encore vue (15).

La poésie de Mario Thériault alterne entre un goût frénétique et fascinant pour le baroque, souvent lié à des éléments $d^{\prime}$ art visuel (ainsi dans l'étrange lien de préhistoire et de contemporain instauré dans les proses de "Lascaux II »), un plaisir de jouer qui l'apparente au renard d'une unquiétante fable (" je lamine mes émotions / mais je suis une bête qui se déchire la jambe / ...je surprends "(10), et un dénonciateur de tout ce quotidien qui étouffe la nouveauté et l'innocence du regard. À ce titre, il n'est pas surprenant que la poésie fasse place aux nombreuses manifestations de quotidien caricaturalement « platte " auquel nous a habitués la poésie acadienne de Moncton depuis les tableaux de backyard de Guy Arsenault : 
il dit dans le confort de son bungalow :

"c'est vraiment beau "

sa femme le silence répond de la tête

sa réflexion est captive d'une autre saison

il dit plus tard: « veux-tu watcher la t.v. ? »

elle dit : « O.K. » (17).

Le quotidien, c'est aussi le faux. Le kitsch. Le quétaine. L'artificiel. « le Vrai est une idée démodée...l'authentique réside désormais dans la simulation annoncée. je te nourris de mes spasmes Monoprix et te fais l'amour à l'ombnre du chêne idyllique de mon Howard-Johnson. ou de mon Holiday Inn. accessoirement »(28). Le quotidien, c'est aussi le sentiment de l'échec : face au mythe, que vaut la réalité ? " aux grandes prétentions les grands espaces. un ciel, il nous étouffe, et notre morbide tendance de n'avoir rien réussi. c'est comme ça. stop it. et on repart comme un sprinter nègre $"(41)$.

Pourtant, à travers les miroirs qui nous renvoient une multiplicité de formes toutes plus étranges et plus artificielles les unes que les autres, il y a chez Mario Thériault une capacité d'expression proprement lyrique qui permet une acuité du regard particulièrement intense. Le marchand de sable, ici, c'est la tempête de sable (mais le sable n'est-il pas semblable à la neige ?) qui décape et dessille le regard :

dans le sable
à chaque jour
je passe
et repasse
le ciel sans fin
que je plie et range
contre les teintes
de notre ruralité (46).

Apprendre à voir : n'est-ce pas, depuis Homère, l'aède aveugle, l'un des buts de la poésie?

je poursuis

prisme

pôle

rien que pour voir (48). 